\title{
The Effect of 4-Week Training with Shoulder Kinesio-Taping on Shooting Accuracy of Young Archers*
}

\section{Olcay Mülazımoğlu', Yakup Akif Afyon ${ }^{1}$, Selçuk Sayılır², Ayşe Salgın ${ }^{3}$}

${ }_{1}^{1}$ Mugla Sitkı Koçman University, Faculty of Sport Sciences, Mugla/TURKEY
${ }^{2}$ Mugla Sitkı Koçman University, Faculty of Medicene, Mugla/TURKEY
${ }^{3}$ Mugla Sitkı Koçman University, Graduate School of Health Sciences, Mugla, TURKEY

*This study was presented in an oral presentation at ERPA International Congresses on Education, between 2-4 June 2016, in Sarajevo / Bosnia and Herzegovina.

\begin{abstract}
The aim of this research is to investigate the effects of exercises done by the kinesio-taping technique with 4-week on target shooting accuracy in young archers using olympic recurve bow. Eight athletes (3 females-5 males) (age: $15.63 \pm 1.85$ years) who competed in different ages and categories were voluntarily participated in the study, with the consent of their families. Athletes trained for 4 weeks through exercising deltoid muscles on the shoulders of grasp arm with a kinesiology tape before training by the help of a specialis. They performed 10 series of arrow shots consisting of three shots a standard olympic recurve bow according to the rules of saloon (18 meter distance) before and after the athletic training. Shooting scores were recorded according to the international scoring system. To determine the difference between the pre-test and post-test shot scores, the paired sample t-test and a correlation analysis between them was performed. The statistical significance (p) value was taken as $<0.05$. Statistically significant difference was found between pre-test and post-test values of average score of the shooters ( $\mathrm{p}<0.05)$. This increase in post-test shooting scores in the archers shows that the kinesio-taping on shoulders positively affects the shooting accuracy during 4 weeks of trainings. The use of this method, which is thought to improve shooting accuracy of archers.
\end{abstract}

Keywords: Archery, Shooting Accuracy, Kinesio-Taping, Olympic recurve bow, Training

\section{INTRODUCTION}

Kinesio-tape techniques and kinesio-taping were developed by Kenzo Kase. The main idea of kinesiotaping technique is that more successful results can be achieved in a banding method similar to the structural properties and flexibility of human skin without limiting the movements of joints. Kinesio Tex $($ Tape is produced from $100 \%$ cotton yarn made of woven polymer elastic fibers, which can be stretched into 55-60\% of its normal length and that is similar to human skin. The aim of this is reducing inflammation and pain, improving performance, providing neuromuscular reduction, preventing damage and accelerating healing by increasing circulation and movement by increasing subcutaneous interstitial area with the purpose of removing the skin (Kase et al.. 2003).
The effects of kinesio-taping has been investigated in the treatment of sports injuries (Akbaş et al., 2011, Chang et al., 2010, Williams et al., 2012), pain relief (Gonzalez- Iglesias et al., 2009; Castro-Sanchez et al., 2012; Chang et al., 2012; Chen et al., 2012), changes in the range of motion (An et al., 2012), and muscle strength (Callegari et al., 2012; Chang et al., 2012; Fratocchi et al., 2013) in previous studies.

Increase of international popularity of kinesiological taping method was begun during the 2008 Beijing Summer Olympics where many athletes in different fields used it for acute and chronic injuries and physiological problems including muscular imbalances, for therapeutic purposes during competitions. Then again, the use of these bands by elite and well-known professional athletes during

This article is published under the terms of the Creative Commons Attribution License 4.0 Author(s) retain the copyright of this article. Publication rights with Alkhaer Publications.

Published at: http://www.ijsciences.com/pub/issue/2018-06/

DOI: 10.18483/ijSci.1685; Online ISSN: 2305-3925; Print ISSN: 2410-4477 
competitions increased the popularity of the band (Osborn, 2009, Çeliker et al., 2011).

There are studies on the positive effects of kinesiotaping (Christou, 2004; Whittingham et al., 2004; Lewis et al., 2005; Hsu et al., 2009; Aktas and Baltaci 2011) whereas there are studies showing that there is no effect of it (Fu et al., 2008; Chang et al., 2010; Bicici et al., 2012; Arslanoglu et al., 2014).

It can be seen that these studies are mostly for therapeutic purposes. The number of studies examining the contribution of the method of taping to healthy athletes for the athletic performance of them is limited (Lumbroso et al., 2014). The prevalence of taping used by high level athletes in sports fields requires to seek answers for the question whether taping practices support performance in sports.

Archery sport is a static sport that requires strength and durability of the upper body, especially the shoulder belly muscles (Ertan et al., 2003). Archery skill requires accurate shooting that finds the target within a certain period of time. Vision is the most important factor in archery. Nishizono et al. (2008) divided the shoting into six phases; bow hold, drawing, full draw, aiming, release and followthrough. An archer pushes the bow with an extended arm, which is statically held in the direction of the target, while the other arm exerts a dynamic pulling of the bowstring from the beginning of the drawing phase, until the release is dynamically executed (Leroyer et al., 1993; Nishizono et al., 2008). The release phase must be well balanced and highly reproducible to achieve commendable results in a competition (Nishizono et al., 2008).

The most important action for archers is back tension. The muscles that work for good back tension are major and minor rhomboids, levator scapula, trapezius and latissumus dorsi. During the pulling, the "lats" is extended to the posterior deltoideal back and helps in rotation. At the same time, Lats stabilizes the middle deltoid muscle for stabilization of the arm, thereby increasing stability in the shoulder joint (Sharma et al., 2015). According to electromyographic data and analysis of previous studies, 32 double-sided muscles function in the upper and lower limbs and body parts of the body during arrow shooting phase. The main muscles that reveal dynamic and high frequency in various parts of the arrow shooting phase come to the forefront. These are radial flexors and ulnar extensor muscles, right and left arm triceps, deltoids and trapezius muscles (Pukhov et al., 2015).

At the full draw stage, the highest shoulder and back muscle tension and activation values should be obtained, and joint control should be provided with the stability of the deltoid and trapezius muscles to reduce humeral shivering (Lin et al. 2010). For this a good training schedule and the prospect of specific work are emerging. It is emphasized that tactile sense plays an important role in controlling joint position and movement. Kase et al. (2003) stated that the increase in proprioceptive functions is due to afferent stimulation to the skin, and may be the effect of kinesio-taping on this mechanism.

Although it can be seen that the kinesio-taping method in healthy athletes in competitions and training is often used whereas the research regardig the effects of it on the performance is limited. In the investigations conducted, there was no clear effect of the kinesio taping practices on the strength. However, there is no clear information about the stability of the upper extremity and whether it increases the technical ability. Therefore, it was aimed to investigate the effect of 4-week kinesio-taping practice on target shooting accuracy of archers using olympic recurve bow in our research.

\section{METHOD}

\section{Participants}

The study was conducted on eight volunteer competitor athletes using the olympic recurve bow after the permission of their parents was taken for the research. They have participated in race at national level in their age categories. The research is based on the Helsinki Declaration criteria. A written consent form was obtained from their parents.

Kinesio-Taping (KT) technique. A $5 \mathrm{~cm}$ wide blue color kinesio tape (Kinesio Tex® Tape) was used for taping. The application technique was applied under the deltoid overhang of the humerus with $50 \%$ stretching of subsections and with the "Y" band technique. The athlete held his/her arm in position at 45 degrees extension and internal rotation while the Y-tape was attached to the anterior part of the deltoid on clavicle. Then, the athlete held his/her arm in position at 30 degrees flexion and internal rotation while the tape attached to the posterior part of the deltoid on clavicle. Acromioclavicular (AC) joints were taped by using I band technique with $100 \%$ stretching in the middle of the tape AC joint KT application was applied on sitting position with rest position of the shoulder. Taping applications were applied by an experienced physiatrist (see Fig. 1).

Shooting Test. Archers used standard olympic recurve bow in training and shooting tests. Each athlete used his own competition bow set in training and shooting tests, because the participants in this study were competitors in different age categories. The athletes performed 10 series of shots consisting of 3 shots according to the rules of olympic recurve bow shooting (18 meter distance) during the training. 
Shooting scores were recorded according to the international scoring system. In scoring, over shooting gets zero "0" points and 6-7-8-9 and 10 points are marked on the target sheet. In the scoring, they could get a score of at least zero and a maximum of 300 points. 120 seconds were given for each series of 3 shots. Breaks were taken between series for control of target paper. The arrow shooting tests have been carried out by a specialist who has Turkish National athlete experience and coaching certificate.

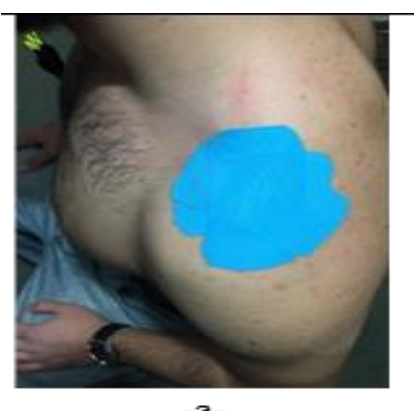

$-\mathrm{a}-$

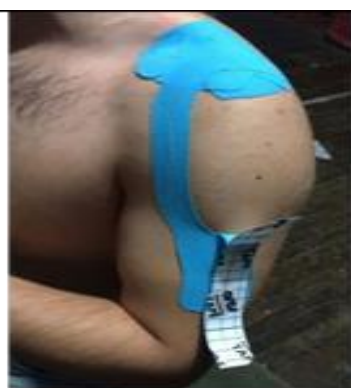

$-\mathrm{b}-$

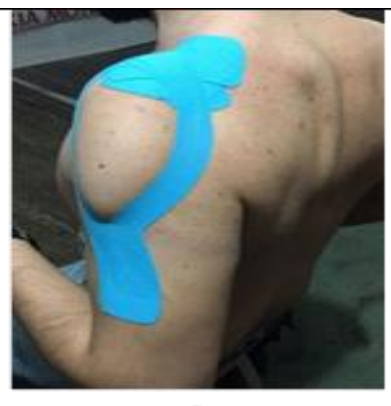

$-\mathrm{c}-$

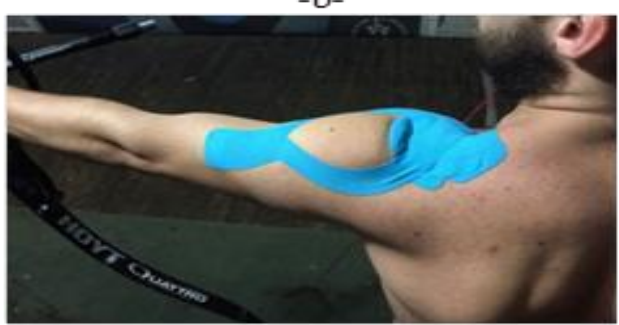

$-d-$

Figure 1. Kinesio-taping application technique

Experimental design. After applying kinesio-taping to participants, they warmed up before the shooting test. They performed the shooting test and their scores were recorded as "Shot Score (pretest)".Kinesio-tape was applied to the athletes before each training sessions throughout four-week. The routine training programs of the athletes for four days a week were not changed. At the end of the fourweek training sessions, all participants performed the shooting test (as in the same pre-test) and their scores were recorded as "Shooting Test (post-test)".

\section{Analysis of Data}

All data are presented as mean \pm standard deviation and statistical significance was set at $\mathrm{p}<0.05$. Statistical analysis was performed with SPSS Version 22. Pearson correlation and paired sample t-test analysis were performed for shot scores pre-test and post-test. The effect size (Cohen's d) of the change between shooting scores is calculated (Cohen, 1988).

\section{RESULTS}

It was found that eight archers' (3 females-5 males) age, weight, height and experience; (respectively, $15.63 \pm 1.85 \mathrm{yrs} ; 60.75 \pm 14.04 \mathrm{~kg} ; 173.63 \pm 8.42 \mathrm{~cm}$; $1.75 \pm 1.39$ yrs). (Table 1$)$.

Table1. Descriptive statistics for the participants.

\begin{tabular}{lcrrrr}
\hline \multicolumn{1}{c}{ Variables } & N & \multicolumn{1}{c}{ Min } & Max & \multicolumn{1}{c}{$\overline{\mathbf{X}}$} & \multicolumn{1}{c}{ Sd } \\
\hline Age (years) & 8 & 12 & 18 & 15.63 & 1.85 \\
Weight (kg) & 8 & 45 & 91 & 60.75 & 14.04 \\
Height (cm) & 8 & 163 & 187 & 173.63 & 8.42 \\
Experience (years) & 8 & 1 & 5 & 1.75 & 1.39 \\
\hline
\end{tabular}

The mean and standard deviation values of the shot score (pre-test) and (post-test) of the subject group were found to be $X 1=224.63 \pm 37.76$ and $\mathrm{X} 2=248.38 \pm 26.01$ point, respectively. There was a significant correlation between pre-test and post-test shooting scores of the archers $(\mathrm{r}=0.93, \mathrm{p}<0.01)$.
There was a statistically significant difference between pre-test and post-test scores $(\mathrm{t}=-4.07$; $\mathrm{p}$ $<0.01)$. The reason for this difference is that there is a significant increase in post-test shot scores. The effect size of this increase (Cohen's d) was found to be high (d> 0.80). (Table 2). 
The Effect of 4-Week Training with Shoulder Kinesio-Taping on Shooting Accuracy of Young Archers

Table2. Shot score of pre-test and post-test comparison analysis

\begin{tabular}{|c|c|c|c|c|c|c|c|c|}
\hline \multirow[t]{2}{*}{ Variable } & \multirow[t]{2}{*}{$\mathbf{N}$} & \multirow[t]{2}{*}{ Min } & \multirow[t]{2}{*}{ Max } & \multirow[t]{2}{*}{$\overline{\mathbf{X}} \pm \mathbf{S d}$} & \multicolumn{2}{|c|}{$\begin{array}{c}\text { t-test } \\
\text { (paired samples) }\end{array}$} & \multirow[t]{2}{*}{$\begin{array}{l}\text { Mean } \\
\text { Diff. } \\
\text { (Sd) }\end{array}$} & \multirow{2}{*}{$\begin{array}{c}\text { Effect Size } \\
\text { (Cohen's } \\
\text { d) }\end{array}$} \\
\hline & & & & & $\mathbf{t}$ & $\mathbf{p}$ & & \\
\hline $\begin{array}{l}\text { Shot score } \\
\text { (pre-test) }\end{array}$ & 8 & 153 & 278 & $224.63 \pm 37.76$ & \multirow{2}{*}{$-4,07 * *$} & \multirow{2}{*}{0.00} & \multirow{2}{*}{$\begin{array}{c}-23,75 \\
(16,525)\end{array}$} & \multirow{2}{*}{$\begin{array}{l}\text { High } \\
(1,437)\end{array}$} \\
\hline $\begin{array}{l}\text { Shot score } \\
\text { (post-test) }\end{array}$ & 8 & 205 & 283 & $248.38 \pm 26.01$ & & & & \\
\hline
\end{tabular}

** indicates significant difference at $\mathrm{p}<0,01$ level

\section{DISCUSSION}

According to the present study findings, there was a significant difference between the mean of shooting score before and after the "four-week shoulder kinesio-taping training" of the archers $(\mathrm{t}=-4.07 ; \mathrm{p}<$ 0.01). This difference is favorable after the training, thus demonstrating that this process improves shot accuracy.

In previous studies, kinesio-tape application was reported to have no effect on strength ability in large muscle groups in healthy subjects ( $\mathrm{Fu}$ et al.,2008; Arslanoglu et al., 2014). However, kinesio-taping has been reported to be beneficial in some treatment or rehabilitation case studies (Nosaka 1999, Frazier et al., 2006, Thelen et al., 2008, Kaya et al., 2011).

Previous some studies reported that effect of kinesiotaping no significant on; ball throwing speed of baseball players (Hikita, 2009); long jump performance of elite tennis players (Schiffer et al., 2015) maximal isometric voluntary knee eccentric force of professional soccer players (Serra et al., 2015) muscle strength of quadriceps and hamstring muscles of young athletes (Fu et al., 2008; Arslanoğlu et al., 2014) and strength of quadriceps muscle group of sedanter and female soccer players (Arslanoğlu et al., 2014). Some of the previous studies reported similar results for upper body strength as well as lower body. Hand-grip strength was no affected kinesio-tape application (Chang et al., 2010) and also no significant difference between kinesiological taping and standard sporting banding effectiveness on basketball players with chronic ankle sprain on quickness, endurance, balance and coordination characteristics of the athletes (Bicici et al., 2012). In some previous studies reporting opposite results, kinesio-taping affected on the balance (Jackson et al., 2016) and jump (Aktas and Baltaci, 2011) performance of the athletes. In medical studies on athletes reported that kinesio-taping exercises caused positive changes (Christou, 2004; Whittingham et al., 2004; Lewis et al., 2005).

In a study examining the effect of warming types on the shooting accuracy of archers, it was reported that static stretching warm-up exercises did not significantly affect the score success, but dynamic warm-up exercises decreased the hit success (Turan and Çilli, 2016). The aim of this studywas parallel ours, was researched how can increase the shooting success of the archers.

We found that the mean post-test scores of the participants were higher than the pre-test scores ( $248.38 \pm 26.0 ; 224.63 \pm 37.76$ points, respectively). "Four-week training with shoulder kinesio-tape" significantly increased the shooting accuracy of athletes. The effect size of this increase in the average shooting score was found to be large.

\section{CONCLUSION AND SUGGESTIONS}

According to the results of this study, it was observed that the training performed by the kinesio-taping method applied to the shoulder joint of the archers using the recurve bow for four weeks had a significantly higher positive effect on archery shooting success of the athletes. For the athletes and coaches, it is considered important to use the kinesiotaping method to improve the shooting performance. In future studies, a greater number of control and test groups can be used to provide detailed information using different taping methods.

\section{Applicable Remarks}

Young archers are benefiting from their work to increase the accuracy of successful shooting with different methods such as kinesio-tape application.

The archers should use the kinesio-taping methods during the trainnig proccess.

In future studies, it should be investigated whether archers increase the bow arm balance by applying kinesio-taping.

\section{REFERENCES}

1. Aagaard, P., Simonsen, E.B., Trolle, M., Bangsbo, J. \& Klausen, K. (1995). Isokinetic hamstring/quadriceps strength ratio: Influence from joint angular velocity, gravity correction and contraction mode. Acta Physiologica Scandinavica, 154: 421-427.

2. Akbaş, E., Atay, AO., \& Yüksel, I. (2010). The effects of 
additional kinesio taping over exercise in the treatment of patellofemoral pain syndrome. Acta orthopaedica et traumatologica turcica, 45(5); 335-341.

3. Aktas, G., \& Baltaci, G. (2011). Does kinesiotaping increase knee muscles strength and functional performance? Isokinetics and Exercise Science, 19(3); 149-155.

4. An, HM., Miller, CG., McElveen, M., \& Lynch, JM. (2012). The effect of kinesio tape ${ }^{\circledR}$ on lower extremity functional movement screen ${ }^{\mathrm{TM}}$ scores. International Journal of Exercise Science, 5(3); 2.

5. Arslanoğlu E, Güzel NA \& Çilli B.( 2014). The effect of kinesiotaping technique on quadriceps muscle strength of healthy subjects. Kafkas J Med Sci, 4(1); 23-26.

6. Bicici, S., Karatas, N., \& Baltaci, G. (2012). Effect of athletic taping and kinesiotaping ${ }^{\circledR}$ on measurements of functional performance in basketball players with chronic inversion ankle sprains. International Journal of Sports Physical Therapy, 7(2); 154.

7. Callegari, D.A., Cordova, C.E., Dunievitz, J.R. (2012). Kinesio taping on short-term changes in shoulder strength in healthy adults: A randomized clinical trial. (Unpublished doctoral dissertation). University of Nevada, Las Vegas.

8. Castro-Sanchez, AM., Lara-Palomo, IC., MataránPeñarrocha, GA., Fernández-Sánchez, M., Sánchez-Labraca, N., \& Arroyo-Morales, M. (2012). Kinesio Taping reduces disability and pain slightly in chronic non-specific low back pain: a randomised trial. Journal of physiotherapy, 58(2); 8995.

9. Chang, HY., Chou, KY., Lin, JJ., Lin, CF., \& Wang, CH. (2010). Immediate effect of forearm Kinesio taping on maximal grip strength and force sense in healthy collegiate athletes. Physical Therapy in Sport, 11(4); 122-127.

10. Chang, HY., Wang, CH., Chou, KY., \& Cheng, SC. (2012) Could forearm kinesio taping improve strength, force sense, and pain in baseball pitchers with medial epicondylitis? Clinical Journal of Sport Medicine, 22(4); 327-333.

11. Chen, SM., Alexander, R., Lo, SK., \& Cook, J. (2012). Effects of Functional Fascial Taping on pain and function in patients with non-specific low back pain: a pilot randomized controlled trial. Clinical Rehabilitation, 26(10); 924-933.

12. Christou, EA. (2004). Patellar taping increases vastus medialis oblique activity in the presence of patellofemoral pain. Journal of Electromyography and Kinesiology, 14(4); 495-504.

13. Cohen J. (1988). The effect size. Statistical power analysis for the behavioral sciences. 77-83.

14. Çeliker, R., Guven, Z., Aydog, T., Bagis, S., Atalay, A., Yagci, HC., \& Korkmaz, N. (2011). The kinesiologic taping technique and its applications/Kinezyolojik bantloma teknigi ve uygulama alanlari. Turkish Journal of Physical Medicine and Rehabilitation, 57(4); 225-236.

15. Ertan, H., Kentel, B., Tümer, ST., \& Korkusuz, F. (2003). Activation patterns in forearm muscles during archery shooting. Human Movement Science, 22(1); 37-45.

16. Fratocchi, G., Di Mattia, F., Rossi, R., Mangone, M., Santilli, V., \& Paoloni, M. (2013). Influence of Kinesio Taping applied over biceps brachii on isokinetic elbow peak torque. A placebo controlled study in a population of young healthy subjects. Journal of Science and Medicine in Sport, 16(3); 245-249.

17. Frazier, S., Whitman, J., \& Smith, M. (2006). Utilization of kinesio tex tape in patients with shoulder pain or dysfunction: a case series. Advanced Healing, 18-20.

18. Fu, TC., Wong, AM., Pei, YC., Wu, KP., Chou, SW., \& Lin, YC. (2008). Effect of Kinesio taping on muscle strength in athletes - a pilot study. Journal of Science and Medicine in Sport, 11(2); 198-201.

19. Gonzalez-Iglesias, J., Fernández-de-Las-Peñas, C., Cleland, J., Huijbregts, P., \& Gutiérrez-Vega, M. DR. (2009). Shortterm effects of cervical kinesio taping on pain and cervical range of motion in patients with acute whiplash injury: a randomized clinical trial. Journal of Orthopaedic \& Sports Physical Therapy, 39(7); 515-521.

20. Hikita, Y. (2009). The acute effects of kinesio taping on throwing velocity in NCAA Division I, II, and III baseball pitchers (Doctoral dissertation, California University of Pennsylvania)

21. Hsu, YH., Chen, WY., Lin, HC., Wang, WT., \& Shih, YF. (2009). The effects of taping on scapular kinematics and muscle performance in baseball players with shoulder impingement syndrome. Journal of Electromyography and Kinesiology, 19(6); 1092-1099.

22. Jackson, K., Simon, JE., \& Docherty, CL. (2016). Extended use of kinesiology tape and balance in participants with chronic ankle instability. Journal of Athletic Training, 51(1); 16-21.

23. Kase K, Wallis J \& Kase T. (2003). Clinical therapeutic application of the kinesio taping method. Tokyo, Japan: Ken Ikai Co Ltd .

24. Kaya, E., Zinnuroglu, M., \& Tugcu, I. (2011). Kinesio taping compared to physical therapy modalities for the treatment of shoulder impingement syndrome. Clinical Rheumatology, 30(2); 201-207.

25. Leroyer, P., Van Hoecke, J., \& Helal, J. N. (1993). Biomechanical study of the final push-pull in archery. Journal of Sports Sciences, 11(1); 63-69.

26. Lewis, J. S., Wright, C., \& Green, A. (2005). Subacromial impingement syndrome: the effect of changing posture on shoulder range of movement. Journal of Orthopaedic \& Sports Physical Therapy, 35(2); 72-87.

27. Lin, JJ., Hung, CJ., Yang, CC., Chen, HY., Chou, FC., \& Lu, TW. (2010). Activation and tremor of the shoulder muscles to the demands of an archery task. Journal of sports sciences, 28(4); 415-421.

28. Lumbroso, D., Ziv, E., Vered, E., \& Kalichman, L. (2014). The effect of kinesio tape application on hamstring and gastrocnemius muscles in healthy young adults. Journal of Bodywork and Movement Therapies, 18(1); 130-138.

29. Nishizono, H., Shibayama, H., Izuta, T., \& Saito, K. (2008, December). Analysis of archery shooting techniques by means of electromyography. In ISBS-Conference Proceedings Archive (Vol.1,No. 1).

30. Nosaka, K. (1999). The effect of kinesio taping ${ }^{\circledR}$ on muscular micro-damage following eccentric exercises. In 15th Annual Kinesio Taping International Symposium Review (pp. 70-73). Kinesio Taping Association Tokyo.

31. Osborn K. (2009). Tape it up: Kinesio taping facilitates movement, while offering support. Massage Body, 24:52-8.

32. Pukhov, AM., Moiseev, SA., Ivanov, SM., \& Gorodnichev, RM. (2015). Laws of motion control in elite archers. Theory and Practice of Physical Culture, (6); 7-7.

33. Schiffer T, Möllinger A, Sperlich B \& Memmert D. (2015). Kinesio taping and jump performance in elite female track and field athletes. Journal of Sport Rehabilitation, 24(1).

34. Serra, MV., Vieira, ER., Brunt, D., Goethel, MF., Gonçalves, M., \& Quemelo, PR. (2015). Kinesio Taping effects on knee extension force among soccer players. Brazilian Journal of Physical Therapy, 19(2); 152-158.

35. Sharma HS, Singh NS \& Singh TB. (2015). Effectiveness of six weeks training on static strength of archery players. IJPESH, 1(5); 34-36.

36. Thelen, MD., Dauber, JA., \& Stoneman, PD. (2008). The clinical efficacy of kinesio tape for shoulder pain: a randomized, double-blinded, clinical trial. Journal of Orthopaedic \& Sports Physical Therapy, 38(7); 389-395.

37. Turan, S., \& Çilli, M. (2016). Farklı 1sınma yöntemlerinin olimpik okçulukta atış performansına etkisi. Online Türk Sağlık Bilimleri Dergisi, 1(1); 13-20.

38. Whittingham, M., Palmer, S., \& Macmillan, F. (2004). Effects of taping on pain and function in patellofemoral pain syndrome: a randomized controlled trial. Journal of Orthopaedic \& Sports Physical Therapy, 34(9); 504-510.

39. Williams, S., Whatman, C., Hume, PA., \& Sheerin, K. (2012). Kinesio taping in treatment and prevention of sports injuries. Sports Medicine, 42(2); 153-164. 